\title{
SOCIO-ECONOMIC IMPACTS OF FESTIVALS AND EVENTS: A CASE STUDY OF THE MZANSI GOLDEN ECONOMY PROGRAMME IN SOUTH AFRICA
}

\author{
Urmilla BOB * \\ University of KwaZulu-Natal, School of Agriculture, Earth and Environmental Sciences, College \\ of Agriculture, Engineering and Sciences, Durban, South Africa, e-mail: bobu@ukzn.ac.za
}

\section{Kamilla SWART}

University of Johannesburg, School of Tourism and Hospitality, Johannesburg, South Africa, e-mail: kamilla@kamilla-sa.co.za

\section{Rivoni GOUNDEN}

University of KwaZulu-Natal, School of Agriculture, Earth and Environmental Sciences, College of Agriculture, Engineering and Sciences, Durban, South Africa, e-mail: rivoni.gounden@gmail.com

\section{Amanda GUMEDE}

University of KwaZulu-Natal, School of Agriculture, Earth and Environmental Sciences, College of Agriculture, Engineering and Sciences, Durban, South Africa, e-mail: agumede505@gmail.com

\section{Sizwe NKAMBULE}

University of KwaZulu-Natal, School of Agriculture, Earth and Environmental Sciences, College of Agriculture, Engineering and Sciences, Durban, South Africa, e-mail: sizwe.nkambule@gmail.com

Citation: Bob U., Swart, K., Gounden, R., Gumede, A. \& Nkambule, S. (2019). SOCIOECONOMIC IMPACTS OF THE FESTIVALS AND EVENTS SUB-CATEGORY OF THE MZANSI GOLDEN ECONOMY PROGRAMME IN SOUTH AFRICA GeoJournal of Tourism and Geosites, 27(4), 1236-1250. https://doi.org/10.30892/gtg.27410-429

\begin{abstract}
The Mzansi Golden Economy (MGE) programme in South Africa is intended to unlock the arts, culture and heritage sector to create sustainable jobs and economic development as well as address social cohesion. This research focuses on one of the main sub-categories, the Festivals and Events Grant Programme of the MGE and investigates the programme for a three year funding cycle period. The methodological approach included an examination of 30 organiser reports submitted to DAC and indepth interviews to examine the spatial distribution, amount and number of years of funding received, types supported, job creation and socio-environmental impacts of the Festivals and Events. A spatial spread across South Africa's nine provinces, different types and sizes of Festivals and Events, job creation, and variation in funding (with reliance on public funding) were noted. The Programme meets the broader objectives of the MGE to contribute to increased diversity of cultural offerings.
\end{abstract}

Key words: The Mzansi Golden Economy (MGE), Festivals and Events, South Africa, culture, impacts, job creation

\footnotetext{
* Corresponding author
} 


\section{INTRODUCTION}

The cultural and creative sector is increasing in prominence with numerous associated benefits including job creation, economic development (including contributing to tourism growth), cultural preservation and regeneration, and promoting social cohesion (Drummond \& Snowball, 2019; Haines et al., 2018; Higgins-Desbiolles, 2016; O'Hagan, 2016; Swart et al., 2018; Throsby, 2016). Specifically, Drummond and Snowball (2019) assert that the creative and cultural industries have become popular policy tools for promoting economic growth and development. However, as Baldi (2018) and Mulino (2016) indicate, despite the potential of the cultural economy, the sector relies heavily on public funding globally. Public funding is justified on the grounds that the cultural and creative sector provides public goods and services (Gertzer, 2017), and have the potential to contribute to economic development and social transformation (O'Hagan, 2016).

A major component of the cultural and creative sector is Festivals and Events. These are viewed as key activities in profiling cultural attributes and interests as well as being a catalyst to market destinations. Hemmonsbey and Tichaawa (2019) show how events can be used for destination branding. Luonila and Johansson (2015) indicate the roles that Festivals and Events play in the regional development of cities with them being increasingly integrated into regional strategy development. Quinn (2019) specifically states that Festivals and Events are a mainstay of urban landscapes, featuring strongly in urban development, regeneration and tourism policies. HigginsDesbiolles (2016) particularly highlights how festivals can be tools for cultural maintenance and revival, cultural sharing and economic opportunities for Indigenous Australian communities. Similarly, Yolal et al. (2016) illustrate the impacts of Festivals and Events on local economic development and resident's well-being. They also highlight the community, cultural and educational benefits of hosting Festivals and Events. Festivals and Events are important in the South African context as well where colonial and apartheid structures and systems systematically undermined and marginalised traditional cultural practices and peoples' ability to explore cultural expressions and genres as well as leverage economic opportunities. Tichaawa (2016), Laing (2018) and Quinn (2019) state that although there is increasing recognition of the socio-economic impacts of Festivals and Events, there has been limited research in this area.

Getz (2019) and Getz and Andersson (2016) underscore the importance of examining the profiles, experiences and impacts of Festival and Events. They assert that this is particularly important in contexts where Festivals and Events are supported by government funding. Andersson et al. (2017) also argue that the quality of events should be examined to permit an assessment of satisfaction levels that can inform future planning and management. Thus, the literature notes the relevance of undertaking research on Festivals and Events. Oyekunle and Sirayi (2018) state that as the creative industries become a high driving force in the international marketplace, it is important to measure their effect on the economy and also on society at large. Swart et al. (2018) assert that in the South African context this type of research is important given that public funds are used to support these events and activities. This study contributes to the body of knowledge pertaining to the impacts of government supporting this sector.

In the South African context, the Mzansi Golden Economy (MGE) programme, initiated by the Department of Arts and Culture (DAC) in 2011, is intended to unlock the arts, culture and heritage sector to create sustainable jobs and economic development as well as address social cohesion. From its inception, the MGE programme has provided substantial funding in different sub-categories, including the Festival and Events Grant Programme. There are limited studies that examine the impacts of the arts, culture and 
heritage sector or creative and cultural industries generally and the MGE programme specifically. This research focuses on the Festivals and Events Grant Programme, by undertaking an investigation of this programme for a three year funding cycle period (2014-2015, 2015-2016 and 2016-2017). The objective of this study is to examine the socio-economic impacts of the Festivals and Events Grant Programme of the MGE by looking specifically at the spatial distribution of Festivals and Events funded, the amount and number of years of funding received, types of Festivals and Events supported, job creation and skills development, and social development and greening initiatives, and the sustainability of the Festivals and Events supported by MGE funding.

The next section briefly examines key literature in relation to the arts, heritage and cultural sector. This sector is also referred to as the cultural and creative industries. Thereafter, an overview of the materials and methodological approach used is provided together with a brief overview of the MGE Programme. This is followed by an analysis of the key findings emanating from the data collection, specifically in relation to the spatial distribution of Festivals and Events funded, the amount and number of years of funding received, types of Festivals and Events supported, employment and job creation and socio-environmental impacts. Finally, concluding remarks are offered.

\section{SECTOR}

IMPACTS ASSOCIATED WITH THE ARTS, CULTURE AND HERITAGE

There are differences in the definitions of what constitutes the arts, culture and heritage sector/ creative and cultural industries. Weber (2017) indicates while this sector is difficult to define, it refers to intellectual property and knowledge products linked to skills and talent. Throsby (2008) notes that cultural heritage is made up of a stock of cultural capital that is passed on from one generation to another, being handed on to future generations. Joffe (2013) argues that the cultural and creative economy places emphasis on goods, services and activities of a cultural/ artistic and/ or heritage nature whose origin are in past or present human activities. Joffe (2013) further asserts that this definition not only includes the output of human creativity and industrial reproduction, but other activities as well that contribute to the creation and distribution of cultural and creative products. Swart et al. (2018) indicate that the cultural and creative industries range from the visual and performing arts to software development in recent years. They further assert that cultural events, performances, shows and exhibitions play an important role to preserve as well as expose society to cultural heritage, contributing to cultural sustainability. In the South African context, Snowball et al. (2017) state that in the South Africa context the arts, culture and heritage sector is conceptualised more broadly to encompass commercial activities, denoted as the cultural and creative industries.

Joffe (2013) states that the cultural and creative economy in Africa should be strengthened and promotes to enhance development in all its dimensions (human, social, ecological and economic) and for growth. Bialostocka (2014) states that the heritage sector in South Africa is a means to preserving the legacy of South Africa's freedom struggle and a possible economy booster through heritage tourism. Goto (2017) argues that governments financially support the cultural and creative sector to further excellence, innovation and access; recognise and celebrate national, regional or local identity; promote continuity; and support diversity. Linked to the commercial value is that heritage is generally viewed as a powerful engine of economic development that is linked to activities such as tourism (World Bank, 2001). The importance of the relationship between cultural heritage and tourism is also highlighted by Throsby (2016) and Torre and Scarborough (2017) who indicate that cultural activities and tourism are 
reciprocally beneficial. van der Merwe (2016) emphasises the importance in South Africa of relevant government departments preserving, transforming and engaging in segmented marketing of the country's cultural assets to sustain and grow cultural tourism in the future. Furthermore, Rogerson and van der Merwe (2016) note that in relation to local development agendas in the global south, heritage tourism can maximise opportunities. Additionally, Kruger and Saayman (2016) state that arts festivals (the focus of this study) are one of the fastest growing segments of events tourism which have considerable economic value. Snowball et al. (2017) state that the cultural and creative industries is seen to offer great potential to create jobs and promote social inclusivity.

This is supported by Gregory (2019) who asserts that the creative industries have been used globally as a lever for economic development and urban regeneration. van den Bosch (2009) shows how artists transmit various forms of cultural capital and generate income. Haines et al. (2018), Mulino (2016) and the United Nations Conference on Trade and Development/ United Nations Development Programme (UNCTAD/ UNDP, 2008) assert that that the cultural and creative industries contribute to job creation and economic growth, and have the potential to further contribute economically. Holden (2007) denotes economic relationships with culture and the creative industries as being linked to direct transfers of product, skills and ideas; the creation of cultural ecologies in which creative industries thrive; and culture forming part of the networks and resources that underpin the creative economy. O'Hagan (2016) indicates that cultural activities contribute to experimentation and innovation which result in breakthroughs and positive impacts which can be commercialised. Furthermore, O’Hagan (2016) states that cultural activities can have economic spillover effects (from direct employment of artists and other staff as well as indirect/ induced/ multiplier impacts from attracting visitors/ tourists and businesses to an area as well as using additional service providers) which contributes to promoting employment, economic growth and balanced regional development.

Ansell (2016) cautions, however, that this instrumentalism by politicians of seizing on music and the cultural industries to deal with problems of unemployment and economic underdevelopment, which the MGE aims to do, is problematic.

Soini \& Birkeland (2014) indicate that sustainable development embedded in fostering global and intra-generational equity and fairness in the distribution of welfare, utilities, and resources must value culture which is key to achieving these objectives. Additionally, they highlight the importance of ensuring people's participation in the use and sharing of cultural capital to make cultural heritage accessible and ensure sustainable heritage preservation. O'Hagan (2016) identifies a key societal outcome of cultural preservation and activities as identity and social cohesion that permits the expression of national/ regional life that characterise a country and/ or specific groups as well as encourages collective enjoyment and audience participation as well as volunteering which promotes a sense of community and group identity. Snowball et al. (2017, p. 295) state that the cultural and creative industries is "one sector that is especially open to, and appreciative of, social diversity in terms of race, class, cultural group and gender".

Snowball et al. (2017) underscore the importance of transformation (referring to black and women economic empowerment) in relation to economic opportunities associated with the cultural and creative industries in the South African context. They assert that transformation in post-apartheid South Africa achieves employment and ownership patterns that are more representative of the demographics of the country. This issue is also relevant globally. As Bell \& Oakley (2015: 5) state, "culture-led economic growth has proved highly unequal in the distribution of benefits". They also note that there are spatial inequalities since cultural commercial activities tend to be 
concentrated in urban areas with larger populations. This is supported by Drummond and Snowball (2019) who state that theory cultural and creative industries cluster in cities where there are higher levels of socio-economic development and better hard and soft infrastructure. The prominence of public funding globally to support the cultural and creative industries is noted by several researchers (Bagwell et al., 2015; Baldi, 2018; Getzner, 2017; Long \& Morpeth, 2016; Mulino, 2016; Petrova \& Hristov, 2016).

Specifically, Bagwell et al. (2015) indicate that different sources of government funding from the public sector is critical for cultural activities, especially for those that are outside commercialised components of the sector. Getzner (2017) argues that public funding for the cultural and creative industries is warranted because this sector is viewed as being part of the public good. Furthermore, Oyekunle \& Sirayi (2018) state that the creative industries are not a self-sufficient production system.

The social and aesthetic value of cultural activities as a public good is justified on normative grounds that include equality (citizens should access and experience culture irrespective of whether they can afford to pay for it or not), freedom of cultural expression which is not dependent on income or resources available and efficiency to support the creation of a cultural ethos/ atmosphere in society and economic opportunities (Getzner, 2017; O’Hagan, 2016).

This is also linked to Bialostocka's (2014) assertion that not all sites and products, irrespective of how well they are publicised or preserved, are economically viable. As the above discussion indicates, there is increasing recognition of the significance of the arts, cultural and heritage sector. However, concerns are expressed in relation to studies that attempt to assess impacts, especially when public funding is used to support cultural activities. For example, King et al. (2016) indicate the difficulties associated with measuring cultural value and what is actually meant by value in cultural contexts. The importance of examining economic impacts and the limited research in this area is highlighted by researchers such as Dalmas et al. (2015), Ellwood and Greenwood (2016) and Torre and Scarborough (2017).

These authors, however, also note the challenges of reducing impacts to economic measures which include how to integrate the social value of expenditure commitments (given that many aspects of the arts and culture sector have intangible value) to overall economic valuations that aim to establish monetary values, how to include indirect contributions to the economy such as the case with cultural tourism, and how to accommodate changes over time which influence cultural demands and trends.

\section{MATERIALS AND METHODS}

A case study approach is used with a focus on the Festivals and Events Grant Programme of the MGE. The MGE is part of DAC's (2016) broader efforts to maintain an efficient, effective, transparent and accountable national arts, culture and heritage dispensation to support the lives of South Africans. According to DAC (2011), a major challenge faced in South Africa is unemployment and the arts, culture and heritage sector is well positioned to contribute to address this challenge by increasing economic growth opportunities and creating jobs. They refer to this sector as the 'new gold' and assert that the MGE aims to unlock both the demand-side and supply-side constraints within the South African cultural economy and promote market development for the arts sector as well as other related sectors such as tourism. Drummond \& Snowball (2019) indicate that the cultural and creative industries is referred to as the 'new gold' in the MGE Guidelines because of their potential to increase economic growth and create jobs. The MGE programme provides funding to cultural events and activities in five sub-categories: 
Festivals and Events, Touring Ventures, Provincial and National Flagships, Public Arts and Miscellaneous. The MGE Festivals and Events Grant Programme is a tool designed to strengthen and grow the arts, culture and heritage sector (National Arts Council of South Africa, n.d.). It aims to assist local organisations in hosting arts and cultural events in communities, and by providing more opportunities for arts organisations and artists to perform and showcase their work. As outlined by the National Arts Council of South Africa (n.d.), the specific objectives of the Programme are to:

- Create a coordinated programme for events and touring exhibitions that will allow the Department to move away from ad hoc funding to strategic funding based on clear programmes and a strategy for events/ festivals and exhibitions.

- Upscale and create extravaganza at existing events and festivals allowing increased diversity of cultural offerings, enhanced quality, more to be offered and/ or over longer duration for the event with economic and social benefits for the location and on ensuring that parts of the events can tour from province to province.

- Increase the audience and exposure that each production receives which in turn will increase the number of jobs/ livelihoods/ income and work these events/ exhibitions create.

- Increase the social cohesion of the country - in particular of the location in question.

- Increase the up-skilling opportunities to arts and culture communities and the tourism sector.

The evaluation of the Festivals and Events sub-category of the MGE focused on three years of funding cycles (2014-2015, 2015-2016 and 2016-2017). A survey was developed by the researchers in discussion with the South African Cultural Observatory (SACO) and DAC who provided the funding as a broader project to monitor and evaluate the 5 sub-categories that comprise the MGE programme. One hundred and fifty three Festivals and Events supported by the MGE programme were identified from information provided by DAC. Purposively selected Festivals and Events organisers from the list compiled from DAC were approached to be interviewed. The sampling approach adopted was purposive to ensure that different types of Festivals and Events were chosen in relation to genre, amount of MGE funding received and spatial/ geographical spread.

The target for the surevys that probed detailed information was $20 \%$ and 30 surveys were successfully completed. Festivals and Events organisers participated in a face-to-face or telephonic interviews. Trained fieldworkers who were postgraduate students at the University of KwaZulu-Natal conducted the interviews. A document analysis was also undertaken in relation to information provided by DAC which included contracts and organiser reports submitted to DAC after the Festival/ Event was held.

\section{RESULTS DISCUSSIONS}

\section{Profile of organisation/ business and diversity of cultural offerings}

Among the 30 Festivals and Events interviewed, the number of times the organisation planned the MGE funded event as well as being involved in organising events ranged from one to 22 years with an average of 3.4 years and 6.7 years, respectively. Only one organiser was involved in organising cultural events/ activities for more than 20 years with most being involved for less than 10 years.

The results show that many of the events have been held longer than the number of years that the MGE programme has been in place. The results indicate that organisers have been involved with planning the event/ activity for a few years and generally organisers have been organising events/ activities for the same period that they have been organising the MGE funded event which suggests that that in several cases, both the event and the organisation are relatively new in the cultural event/ activity arena. 
This supports assertions by DAC (2016/ 2017) that government funding (in this case via the MGE programme) is creating opportunities for new entrants into the sector and for more cultural events/ activities to be held in South Africa, contributing to the MGE objective of increasing and diversifying cultural offerings. It is important to note that the impacts are beyond hosting a cultural Festival or Event but also reflect that opportunities are being created for relatively young organisations (and persons within these organisations) to conceptualise, plan and manage cultural events/ activities.

This has broader impacts related to capacity and skills development. The type of organisation/ business that planned the MGE funded events/ activities were mainly NonProfit Organisations (NPOs) (43.3\%). Equal proportions (26.7\%) of the rest of the organisations interviewed were Closed Corporations and Proprietary Limited businesses. One event/ activity was a Section 21 company.

\section{Spatial distribution of Festivals and Events supported}

In terms of the spatial distribution of the Festivals and Events sub-category, results from documentary analysis presented in Table 1 reveal that events/ activities were hosted in all nine provinces with the most dominant provinces being Gauteng (34.6\%), Limpopo (14.5\%), KwaZulu-Natal (13.8\%) and Western Cape (11.2\%). The provinces with fewer Festivals and Events supported were the more rural provinces. The results reveal the spatial inequalities in the distribution of cultural activities as indicated by Bell \& Oakley (2015) and Drummond \& Snowball (2019). Specifically, the clustering of Festivals and Events in the more urban-based provinces (Gauteng, KwaZulu-Natal and Western Cape) with higher populations is evident. However, in the South African context there seems to be a concerted effort by DAC to ensure geographical spread of the Festivals and Events supported by the MGE programme with all nine provinces hosting these activities.

Table 1. Provincial distribution of Festivals and Events ( $n=153)$

\begin{tabular}{|l|c|c|}
\hline & Frequency & Percentage \\
\hline Eastern Cape & 11 & 7.2 \\
\hline Free State & 4 & 2.6 \\
\hline Gauteng & 53 & 34.6 \\
\hline KwaZulu-Natal & 21 & 13.8 \\
\hline Limpopo & 22 & 14.5 \\
\hline Mpumalanga & 3 & 2.0 \\
\hline Northern Cape & 2 & 1.3 \\
\hline North West & 3 & 2.0 \\
\hline Western Cape & 17 & 11.2 \\
\hline No information/ could not be determined & 16 & 10.5 \\
\hline
\end{tabular}

\section{Funding and economic aspects}

While 2 of the 30 respondents did not indicate how many years they received MGE funding, among the rest $13(43.3 \%)$ had funding for one year during the three year reporting period and 50\% received funding for multiple years. Only three (10\%) were funded for all three years. Most (66.7\%) had funding for 2015/2016 while 40\% received funding for $2016 / 2017$ and $23.3 \%$ for $2014 / 2015$ (Figure 1). This indicates that the Festivals and Events were not supported for the entire three year period. This is aligned to the MGE framework to create opportunities for many cultural activities and organisations. Furthermore, as indicated earlier, many of the organisers are relatively new in organising events/ activities in the cultural sector. Among the 153 Festivals and Events funded during the three year period, different levels of funding were received and 
ranged from R30 ooo to R4 ooo ooo. Forty percent of the respondents stated that there were no sponsors other than MGE funding. Among the rest of the events/ activities, sponsors identified were mainly local and provincial government departments. This indicates the reliance on public funding which is of concern given that for all the event/ activities MGE is already a main sponsor. Other sponsors included media partners, organisations (mainly in the arts sector) and retail and private companies. These were far fewer than the public sector sponsors. It is important to note that a few of the organisers indicated that some of the sponsorships (generally from the private sector) were in-kind (advertisements and meals were specifically mentioned). The total amount of sponsorship received from both public and private sources ranged from R200 ooo to R11 208750 with an average of R1 $153 \mathrm{O} 60$ for the last year that the organiser received funding. The results again reflect the high levels of variation among the Festivals and Events supported. It is important to note that most of the respondents $(60 \%)$ stated that there were no sponsors other than the MGE funding, again denoting the heavy reliance on public funding. The average proportion of total sponsorship the MGE funding made up was $83 \%$.

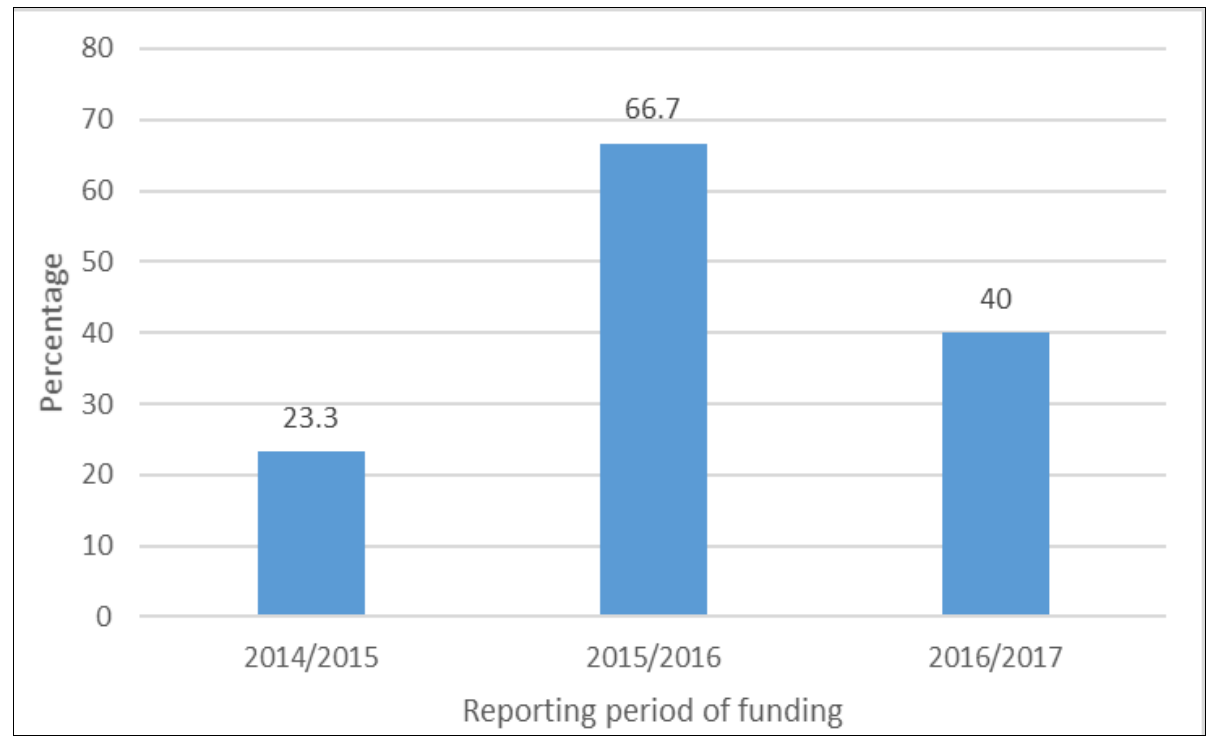

Figure 1. If MGE funded the event/ activity for the last 3 years/ reporting periods (yes responses only, $n=30-$ in \%)

\section{Job creation and skills development}

As indicated in the literature review section, a major factor that influences public funding in developing contexts of the cultural sector is the assumption that jobs will be created and economic growth will be enhanced. Among the Festivals and Events surveyed, the number of people the business/ organisation receiving MGE funding generally employed on a permanent basis ranged from two to 58 (Table 2). The average number of persons employed permanently in the organisation was 8.4. In addition to general permanent employment practices on an annual basis for the last year that MGE funding was received, respondents were asked about the number of people the business/ organisation employed during the course of the year on a permanent basis who work directly with the MGE funded event/ activity. The results ranged from two to 58 persons as well with an average of 9.3 . For $66.7 \%$ of the events/ activities, the 
number of persons employed permanently in the organisations were also the number of permanently employed persons who worked on the MGE event/ activity.

It is interesting to note that more permanently employed persons for the MGE event/ activity than generally permanently employed persons were identified for two Festivals/ Events. The discrepancy was not explained but suggests that organising the MGE funding event/ activity results in more permanently employed persons in the organisation which aligns to the MGE objective of promoting job creation.

The results suggest that in many of the organisations that the MGE funds, Festivals/ Events are one of the main activities or the only activity the organisations are involved in. This again indicates the importance of MGE funding in promoting and supporting the diversity of cultural events/ activities in South Africa.

Table 2. Summary of number of people business/ organisation employs during the course of the year on a permanent basis generally and on a permanent basis who work directly with the MGE funded event/ activity $(\mathrm{n}=30$, in \%)

\begin{tabular}{|c|c|c|}
\hline $\begin{array}{c}\text { Number of persons employed } \\
\text { on a permanent basis }\end{array}$ & $\begin{array}{c}\text { In the } \\
\text { organisation }\end{array}$ & $\begin{array}{c}\text { In the organisation who work with } \\
\text { the MGE funded event/ activity }\end{array}$ \\
\hline None & $6.7 \%$ & $10 \%$ \\
\hline Average & 8.4 & 9.3 \\
\hline Range & None-40 & None-58 \\
\hline
\end{tabular}

Given that an average of 9.3 persons were employed on a permanent basis in the organisation who worked with the MGE funded event/ activity and that 153 events/ activities were funded by the Festivals and Events programme, 1423 permanent jobs are associated with the MGE Festivals and Events programme.

In addition to assisting with the MGE funded event/ activity, other functions of permanent employees were organisational administration and business operations, logistical and transport support, skills and career development in the arts and culture, programme/ event coordination and management, marketing and advertising, sales and fundraising, catering, security aspects, community outreach and school art projects .

Table 3. Number of additional persons employed to assist in the

Preparation for or during the event/ activity, excluding volunteers for the last

reporting year the organisation received MGE funding categorised into groups $(n=30)$

\begin{tabular}{|l|c|c|}
\hline & Frequency & Percentage \\
\hline No response/ not applicable & 4 & 13.3 \\
\hline Less than 10 & 3 & 10.0 \\
\hline $10-20$ & 5 & 16.7 \\
\hline
\end{tabular}

It is worth noting that several of the events/ activities specifically indicated direct involvement in developing and promoting cultural skills, education and research. For example, one organiser assisted with organising and conducting drama classes as well as the promotion and production of theatre plays. Another promoted artistic development and taught artistic skills. A few of the organisers focused on youth education and empowerment activities. These examples reveal that some MGE funded organisers are contributing to cultural development in South Africa in addition to the specific Festival/ Event being supported. Skills development in the creative and cultural sector is being enhanced which aligns to the achievement of the broader objectives of the MGE programme. Table 3 shows that the number of additional persons employed to 
assist in the preparation for or during the event/ activity (excluding volunteers) for the last reporting year the organisation received MGE funding ranged from 5 to 610. The average number of additional persons employed was 95 .

The profile of the additional persons employed were also established with most employed on a temporary/ casual basis for a day, more than a day to a week, more than a week to a month and more than a month. While fewer respondents provided disaggregated information on gender, historical racial category and location of additional persons employed; trends were noted among those organisers who were able to provide the information. No substantial major differences are noticeable in relation to the employment of males compared to females. However, it is apparent that both women and men (although mostly on a temporary/ casual basis) are being exposed to job and skills development opportunities in the arts, cultural and heritage sector.

Among the additional persons employed, in terms of historical population groups, mostly Africans were employed generally for a day, more than a day to a week or more than a week to a month. Therefore, Africans (who are the key equity target group in South Africa) are benefitting from the MGE programme as per its stated objectives. The temporary/ casual nature of the employment that pervades the sector is of concern since this is indicative of a lack of job security in the creative and cultural industries and generally reflects lower paying jobs. This concern is also highlighted by Bell \& Oakley (2015) in relation to job creation in the creative and cultural industries more generally. Mostly locals who worked for a day or more than a day to a week were employed as additional persons. With the exception of one additional person employed permanently nationally for the MGE funded event/ activity, the rest were locally-based (that is, from the city/ town/ municipality where the event is held).

The again reveals that the MGE objective of focusing on locally-based job creation and opportunities in the creative and cultural industries is being met. A range of roles and functions were performed by the additional persons employed, with the main ones being technical support, ddministrative support, infrastructural support, sales and marketing and artists/ participant management as shown in Table 4.

Table 4. Main roles and functions peformed by additional persons employed $(n=30)$

\begin{tabular}{|l|c|c|}
\hline & Frequency & Percentage \\
\hline Technical support & 19 & 63.3 \\
\hline Administrative support & 17 & 56.7 \\
\hline Infrastructural support & 17 & 56.7 \\
\hline Sales and marketing & 17 & 56.7 \\
\hline Artists/ participant management & 16 & 53.3 \\
\hline
\end{tabular}

The results show that additional persons employed were being exposed to a range of different types of skills. In additional to persons receiving remuneration, $46.7 \%$ of the Festivals and Events organisers interviewed indicated that they had work-integrated learning or volunteers for the event which ranged from 1 to 175 with and average of 20 . Training and skills development opportunities are also provided.

\section{Social development and greening initiatives}

As highlighted by Bialostocka (2014) and Soini \& Birkeland (2014), supporting cultural events has impacts beyond economic contributions. The survey included questions on whether the Festival or Event resulted in social development and greening initiatives. Ninety percent of the respondents stated that the event/ activity supported 
by MGE funding initiated social/ charitable initiatives to contribute to social inclusivity, cohesion and empowerment while $10 \%$ did not. This question was prefaced by a statement that "cultural events/ festivals/ activities are linked with social impacts that con contribute to social inclusivity, cohesion and empowerment" which aligned to stated MGE objectives. Among the respondents who stated that social/ charitable initiatives were activated, several were identified, namely, education $(60 \%)$, youth (50\%), culture/ arts (43.3\%), disability (26.7\%) and rural (20\%) programmes. The results indicate that the Festivals and Events are contributing to addressing social issues which is a key component of the MGE programme. Respondents were also asked what MGE funded events/ activities (such as the one the organisation is involved in) can do to be socially responsible. Suggestions were forwarded by $90 \%$ of the respondents with the main ones relating to uplifting communities and disadvantaged groups in particular (such as the youth and persons with disabilities), promoting social cohesion and diversity, supporting education and training programmes/ skills development, supporting and empowering artists (including providing scholarships and bursaries), and building local community pride and identity. Thus, the event organisers highlighted that more could be done to meet the MGE objective of enhancing social cohesion in specific locations via their respective events/ activities.

Audience exposure to cultural activities is also important in relation to promoting social cohesion and strengthening positive social identities. Furthermore, as Throsby (2016), Torre and Scarborough (2017) and van der Merwe (2016) indicate, cultural events/ activities can contribute to tourism. The numbers of persons attending the Festivals and Events from information derived from the surveys and the reports submitted to DAC ranged from 100 to 45000 with an average of 5153 .

This again is indicative of the diversity in relation to the types of events/ activities supported. Many of the respondents stated that some of the persons in attendance (especially for the larger Festivals and Events) were tourists. With an average of 5153 persons attending and given that 153 events/ activities were funded in this category, 788409 persons were exposed to Festivals and Events. The possible range is likely to be between 630727 (a 20\% underestimate) to 946091 (a 20\% overestimate).

Sixty percent of the respondents stated that the event/ activity supported by MGE funding initiated greening initiatives to reduce negative environmental impacts and be more environmentally responsible while the rest did not.

This question was prefaced by a statement that "there is increasing concern over the impacts of events, festivals or activities on the environment”. Among the respondents who indicated that greening initiatives were activated, several types were identified with the main initiatives being proper disposal of waste (43.3\%), recycling (33.3\%), conserving water (23.3\%) and promoting green behavioural change/ information on environmentally-friendly behaviour (20\%). Respondents were also asked what MGE funded Festivals and Events (such as the one the organisation is involved in) can do to be environmentally responsible. Again, 90\% of the respondents provided suggestions which included conserving water and energy, proper disposal of waste, using more environmentally friendly products, promoting recycling, and enabling environmental awareness and education at events/ activities. Associating the events/ activities with pro-environmental messaging was specifically highlighted. While environmental aspects are not directly stipulated in the MGE objectives, this is an important component of sustainability. It is pleasing to note that many of the MGE Festivals and Events are considering environmental issues. 


\section{Sustainability of Festivals and Events}

All the respondents, with the exception of two, pointed out that their respective organisations planned to have this event/ activity next year. The two respondents who indicated that they did not plan to have the event/ activity stated that funding was the key issue. While $70 \%$ of the respondents noted that the organisation would have the event/ activity next year or in the future without MGE funding, the rest (30\%) would not. The main reason was funding constraints since MGE is the main and, in many cases, only funder of the event/ activity. As one respondent stated, "the MGE funding is the only source funding for this event and without it there are limited financial resources to organise the event". Respondents were asked to rate on a scale of 1-5, where 1 is not at all important and 5 is very important, how important MGE funding was for specific aspects outlined in Table 5. The results indicate that in respect to all aspects (financial, status or recognition of event, quality of cultural aspects, ability to include local communities and artists, promotion of social cohesion, and skills and employment in the cultural sector), the importance of MGE funding was highly rated.

The results further suggest that, according to the event organisers, MGE funding is having a positive impact on cultural promotion, social cohesion, skills development and employment creation as well as event/ activity financial sustainability. Thus, from their perspective, the MGE objectives are being met.

Table 5. Rating of statements in relation to specific aspects regarding the importance of MGE funding for various aspects of the event on a scale of 1-5 where 1 is not at all important and 5 is very important $(\mathrm{n}=30$, in \%): Multiple responses

\begin{tabular}{|l|c|c|c|c|c|c|}
\hline Importance of MGE funding for: & 1 & 2 & 3 & 4 & 5 & No response \\
\hline The financial sustainability of the event/ activity & - & - & - & 6.7 & 90.0 & 3.3 \\
\hline The status or recognition of the event & - & - & 3.3 & 16.7 & 76.7 & 3.3 \\
\hline The quality of the cultural aspects & - & - & - & 20.0 & 80.0 & - \\
\hline Ability to include local communities and artists & - & - & 3.3 & 16.7 & 80.0 & - \\
\hline Promote social cohesion & - & - & 3.3 & 23.3 & 73.3 & - \\
\hline $\begin{array}{l}\text { Improve skills and employment opportunities } \\
\text { in the cultural sector }\end{array}$ & - & 6.7 & 3.3 & 23.3 & 66.7 & - \\
\hline
\end{tabular}

\section{CONCLUSION}

The evaluation is based on an analysis of 30 Festivals and Events and assessments of documents submitted to DAC which the researchers had access to. The MGE Festivals and Events Grant Programme aims to strengthen and grow the arts, culture and heritage sector in South Africa, and to assist local organisations in hosting arts and cultural events in communities by providing more opportunities for arts organisations and artists to perform and showcase their work. The results indicate that the MGE Festivals and Events Grant has assisted new organisers in the cultural event/ activity arena. The MGE programme is therefore creating opportunities to support more and new forms of cultural events/ activities to be supported in South Africa.

This indicates that the MGE objective of increasing and diversifying cultural offerings within the country is being achieved in relation to the Festivals and Events sub-category. These opportunities also provide a platform for skills development in the creative and cultural industries that include event management, administration and logistical capacity development. The Festivals and Events displayed a range of different types of cultural genres and aspects including festivals, exhibitions, performances, workshops and training events (mainly targeting youth and schools). Given the diversity 
of cultural events/ activities that are supported by the MGE programme, it is clear that audiences throughout the country are being exposed to different types and genres of cultural events/ activities which is one of the objectives of the programme.

The different types, sizes and spatial/ geographical spread of the Festivals and Events is meeting the broader objective of contributing to increased diversity of cultural offerings. While the dominance of the more populated and urban provinces is evident in relation to the geographical spread, there is certainly a concerted effort by DAC to ensure that Festivals and Events are supported in all provinces.

The results show that jobs generated from the hosting of the event/ activity is largely temporary or casual in nature. However, Festivals and Events are creating permanent jobs as well which can be sustained if these become annual activities which can be complemented by additional cultural offerings that the organisations can become involved in. Temporary/ casual employees as well as volunteers are being exposed to much needed skills development and training opportunities.

Several of the events/ activities specifically indicated direct involvement in developing and promoting cultural skills, education and research; thus contributing to cultural development in South Africa beyond that of the event/ activity being funded. They are enhancing skills development in the creative and cultural sector which is one of the objectives of the MGE programme. Event management skills are being enhanced through the Festivals and Events programme positioning event organisers to host other events within the arts, cultural and heritage sector. From a transformation and empowerment perspective, it is also important to note that both men and women, blacks and locals benefit from jobs created which is a key objective of the MGE programme. The MGE funding further supported, in many instances, small enterprises.

A major concern emanating from this study is the substantial reliance on public funding (especially the MGE programme). For most Festivals and Events, public sponsors are the main and oftentimes only sponsor. DAC has a long-term objective of reducing reliance on their funding. To achieve this, it is imperative that organisations supported via the MGE programme receive training on how to leverage sponsorships from the private sector and increase income generating opportunities associated with the Festivals and Events, such as having exhibitions and stallholders as well as increasing ticket sales. Another key objective of the MGE Festivals and Events Grant is to increase social cohesion and social benefit for the location. The majority of event organisers stated that the event/ activity supported by MGE funding initiated social/ charitable initiatives to contribute to social inclusivity, cohesion and empowerment. The main initiatives were education, culture/ arts, youth, and rural programmes.

The link to cultural/ arts social initiatives is once again underscored and contributing to the MGE objective to strengthen and grow the arts, culture and heritage sector. Sustainability is also highlighted as a key issue in relation to the objectives of the MGE programme. Most Festivals and Events supported by MGE funding are involved in greening initiatives with the main aspects being proper disposal of waste, recycling, promoting green behavioural change/ information on environmentally-friendly behaviour and conserving water. This study indicates that supporting the creative and cultural industries can have multiple benefits.

The Festivals and Events sub-category of the MGE programme is playing a major role in supporting the arts, culture and heritage sector. The results suggest, however, that the over-reliance on public funding requires further research and policy attention to ensure longer term sustainability of these types of cultural activities. This study illustrates the importance of undertaking research to assess the impacts of publicly funded cultural events/ activities as part of a broader monitoring and evaluation effort. 


\section{Aknowledgments}

The research was funded by SACO which is supported by DAC. Thanks to colleagues from both SACO and DAC for their inputs and critiques.

\section{REFERENCES}

Andersson, T., D., Armbrecht, J., \& Lundberg, E., (2017). Linking event quality to economic impact: A study of quality, satisfaction, use value and expenditure at a music festival. Journal of Vacation Marketing, 23 (2), 114-132.

Ansell, G., (2016). Who's got the map? Scholarship, journalism and essentialism in writing on South African Jazz. The World of Music, 5 (2): 125-142.

Bagwell, S., Corry, D., \& Rotheroe, A. (2015). The future of funding: Options for heritage and cultural organisations. Cultural Trends, 24 (1): 28-33.

Baldi, C., E. (2018). Public funding in cultural sector. The arduous process for shared guidelines. Aedon, 2: 1-7.

Bell, D., \& Oakley, K. (2015). Cultural Policy. London: Routledge.

Bialostocka, O. 2014. Using the past to build the future: a critical review of the Liberation Heritage Route (LHR) Project of South Africa. Africa Insight, 44(2), pp.94-107.

Dalmas, L., Geronimi, V., Noël, J., F., \& Sang, J., T., K. (2015). Economic evaluation of urban heritage: An inclusive approach under a sustainability perspective. Journal of Cultural Heritage, 16 (5): 681-687.

Drummond, F., \& Snowball, J. (2019). Cultural clusters as a local economic development strategy in rural, small town areas: The Sarah Baartman District in South Africa. Bulletin of Geography. Socio-economic Series, 43 (43): 107-119.

Ellwood, S., \& Greenwood, M. (2016). Accounting for heritage assets: Does measuring economic value 'kill the cat'? Critical Perspectives on Accounting, 38: 1-13.

Getz, D. (2019). Wine and food events: Experiences and impacts. In Wine Tourism Destination Management and Marketing (pp. 143-164). Palgrave Macmillan, Cham.

Getz, D., \& Andersson, T. (2016). Analysing whole populations of festivals and events: An application of organisational ecology. Journal of Policy Research in Tourism, Leisure and Events, 8 (3): 249-273.

Getzner, M. (2017). The role of governments in conserving and funding cultural institutions. In The Public or Private Goods? (pp. 223-252). Edward Elgar Publishing.

Goto, K. (2017). Why do governments financially support the creative industries? In Tax Incentives for the Creative Industries (pp. 21-31). Springer, Singapore.

Gregory, J., J. (2019). Creative industries and neighbourhood change in South African cities. In The Geography of South Africa (pp. 203-211). Springer, Cham.

Haines, R., Lutshaba, U., \& Shelver, A. (2018). Cultural and creative industry trends. SACO: Nelson Mandela University, Port Elizabeth.

Hemmonsbey, H., \& Tichaawa, T., M. (2019). Using non-mega events for destination branding: A stakeholder perspective. GeoJournal of Tourism and Geosites, 24 (1): 252-266.

Higgins-Desbiolles, F. (2016). Sustaining spirit: A review and analysis of an urban Indigenous Australian cultural festival. Journal of Sustainable Tourism, 24 (8-9): 1280-1297.

Holden, J., (2007). Publicly-funded culture and the creative industries. Arts Council England.

Joffe, A. (2013). The cultural and creative economy in Africa: Challenges and innovations. Report prepared for the UNDP Creative Economy Report.

King, L., Stark, J., F., \& Cooke, P. (2016). Experiencing the digital world: The cultural value of digital engagement with heritage. Heritage and Society, 9 (1): 76-101.

Kruger, M., \& Saayman, M. (2016). Are you willing to pay more for the arts? Journal of Economic and Financial Sciences, 9 (2): 392-408.

Laing, J. (2018). Festival and event tourism research: Current and future perspectives. Tourism Management Perspectives, 25: 165-168.

Long, P., \& Morpeth, N., D. (2016). Introduction. In Tourism and the Creative Industries. Routledge.

Luonila, M., \& Johansson, T. (2015). The role of festivals and events in the regional development of cities: Cases of two Finnish cities. Event Management, 19 (2): 211-226.

Mulino, I., I. 2016. New challenges for cultural activities facing globalisation and digitisation. L'industria, 2: 225-236.

O'Hagan, J. (2016). Objectives of arts funding agencies often do not map well on to societal benefits. Cultural Trends, 25 (4): 249-262.

Oyekunle, O., A., A., \& Sirayi, M. (2018). The role of creative industries as a driver for a sustainable economy: A case of South Africa. Creative Industries Journal, 11 (3): 225-244. 
Petrova, P., \& Hristov, D. (2016). Collaborative management and planning of urban heritage tourism: Public sector perspective. International Journal of Tourism Research, 18 (1): 1-9.

Quinn, B. (2019). A comment on: Arts festivals, urban tourism and cultural policy. Journal of Policy Research in Tourism, Leisure and Events, 11 (sup1): s8-s12.

Rogerson, C., M., \& van der Merwe, C., D. (2016). Heritage tourism in the global South: Development impacts of the cradle of humankind world heritage site, South Africa. Local Economy, 31 (1-2): 234-248.

Snowball, J., Collins, A., \& Tarentaal, D. (2017). Transformation and job creation in the cultural and creative industries in South Africa. Cultural Trends, 26 (4): 295-309.

Soini, K., \& Birkeland, I. (2014). Exploring the scientific discourse on cultural sustainability. Geoforum, 51: $213-223$.

Swart, K., Bob, U., Nkambule, S., \& Gumede, A. (2018). Economic impacts of the touring ventures sub-category of the Mzansi Golden Economy programme in South Africa. EuroEconomica, 2 (37): 90-103.

Throsby, D. (2008). Linking ecological and cultural sustainability. Int. J. Divers. Organ. Communities Nations, 8 (1): $15-20$.

Throsby, D. (2016). Tourism, heritage and cultural sustainability: Three 'golden rules'. In Girard, L., G. \& Nijkamp, P. (eds) Cultural Tourism and Sustainable Local Development (pp. 31-48). Surrey: Ashgate.

Tichaawa, T.M. (2016). The geography of festival and tourism development: the case of Cameroon. In

R. Donaldson, G. Visser, J. Kemp \& J. de Waal (eds.), Proceedings of the Centenary Conference of the Society of South African Geographers (pp. 219-225). Bloemfontein: Society of South African Geographers.

Torre, A., \& Scarborough, H. (2017). Reconsidering the estimation of the economic impact of cultural tourism. Tourism Management, 59: 621-629.

van den Bosch, A. (2009). Professional artists in Vietnam: Intellectual property rights, economic and cultural sustainability. J. Arts Manage. Law Soc., 39 (3): 221-236.

van der Merwe, C., D. (2016). Tourist guides' perceptions of cultural heritage tourism in South Africa. Bulletin of Geography. Socio-economic Series, 34: 117-130.

Weber, A., S. (2017). Creative industries tourism in Qatar: Economy diversification through arts and heritage development. In 4th International Scientific Conference ToSEE-Tourism in Southern and Eastern Europe 2017 "Tourism and Creative Industries: Trends and Challenges" Opatija, Croatia, 4-6 May 2017 (pp. 645-655). Faculty of Tourism and Hospitality Management, University of Rijeka.

Yolal, M., Gursoy, D., Uysal, M., Kim, H., L., \& Karacaoğlu, S. (2016). Impacts of festivals and events on residents' well-being. Annals of Tourism Research, 61: 1-18.

*** DAC. (2011). Mzansi's Golden Economy: Contribution of the arts, culture and heritage sector to the new growth path. South African Department of Arts and Culture. http://www.gov.za/sites/www.gov.za/files/mzansi2ogolden2oeconomy\%2020110411.pdf.

*** DAC. (2016). Mzansi Golden Economy (MGE) guidelines: Criteria, eligibility, processes and systems. http://www.dac.gov.za/sites/default/files/eForms/2016-17-guidelines-for-mzansi-golden-economy1-o-final.pdf.

*** DAC. (2017). Revised White Paper on Arts Culture and Heritage. Revised 3rd draft. http://www.dac. gov.za /sites/default/files/Legislations\%2oFiles/Revised\%203rd\%20Draft\%20RWP\%200n\%20ACH\%2OFEB RUARY\%202017_o.pdf.

*** National Arts Council of South Africa. (n.d.). Mzansi Event and Festival Grant Programme. http://www. nac.org.za/media/news/mzansi-golden-economy-event-and-festival-grant-programme. Department of Arts and Culture.

*** UNCTAD/ UNDP. (2008). Creative Economy Report 20o8: The Challenge of Assessing the Creative Economy: Towards Informed Policy-Making. Geneva: United Nations.

*** World Bank. (2001). Cultural Heritage and Development: A Framework for Action in the Middle East and North Africa, Orientations in Development Series, Middle East and North Africa Region, World Bank, Washington D.C.

Submitted:

17.08.2019
Revised:

09.12.2019
Accepted and published online

12.12.2019 